INFLAMMATORY BOWEL DISEASE

\title{
Trichuris suis therapy in Crohn's disease
}

\author{
R W Summers, D E Elliott, J F Urban Jr, R Thompson, J V Weinstock
}

Gut 2005;54:87-90. doi: 10.1136/gut.2004.041749

See end of article for authors' affiliations

.....................

Correspondence to:

Dr R W Summers, James A

Clifton Center for Digestive

Diseases, Department of

Internal Medicine,

University of lowa Roy J

and Lucille A Carver

College of Medicine, 200

Hawkins Drive, lowa City,

IA 52242, USA;

robert-summers@

viowa.edu

Revised version received

28 March 2004

Accepted for publication

9 April 2004

\begin{abstract}
Background: Crohn's disease is common in highly industrialised Western countries where helminths are rare and uncommon in less developed areas of the world where most people carry worms. Helminths diminish immune responsiveness in naturally colonised humans and reduce inflammation in experimental colitis. Thus exposure to helminths may help prevent or even ameliorate Crohn's disease.

Aims: The aim of the study was to determine the safety and possible efficacy of the intestinal helminth Trichuris suis in the treatment of patients with active Crohn's disease.

Patients: Twenty nine patients with active Crohn's disease, defined by a Crohn's disease activity index $(C D A l) \geqslant 220$ were enrolled in this open label study.

Methods: All patients ingested 2500 live T suis ova every three weeks for 24 weeks, and disease activity was monitored by CDAI. Remission was defined as a decrease in CDAl to less than 150 while a response was defined as a decrease in CDAl of greater than 100.

Results: At week 24, 23 patients (79.3\%) responded (decrease in CDAl $>100$ points or CDAl $<150$ ) and $21 / 29(72.4 \%)$ remitted (CDAl $<150)$. Mean CDAl of responders decreased 177.1 points below baseline. Analysis at week 12 yielded similar results. There were no adverse events.

Conclusions: This new therapy may offer a unique, safe, and efficacious alternative for Crohn's disease management. These findings also support the premise that natural exposure to helminths such as $T$ suis affords protection from immunological diseases like Crohn's disease.
\end{abstract}

\footnotetext{
$\mathrm{C}$
} rohn's disease is a chronic relapsing inflammatory reaction that may affect any part of the gastrointestinal tract. It is common in parts of the world where helminthic colonisation is rare and uncommon in those areas where most people carry worms. ${ }^{1}$ It appears to result from an inappropriate immune response to normal gut flora. Helminths down-modulate the host immune response to unrelated antigens, ${ }^{2-4}$ a property that could be beneficial in Crohn's disease. Helminths reduce inflammation in experimental murine colitis. ${ }^{15-7}$ Trichuris suis, the porcine whipworm, is similar to human whipworm T trichiura. Ingestion of $T$ suis ova results in short term self limited colonisation of humans. ${ }^{8}$ We therefore conducted a 24 week clinical trial to evaluate the safety and possible efficacy of live $T$ suis therapy in Crohn's disease.

\section{METHODS}

Patients were enrolled in a 24 week open label study after giving informed consent. The University of Iowa Institutional Review Board approved the protocol. Subjects with Crohn's disease, as defined by standard clinical, radiological, and histological criteria, were recruited and followed at the University of Iowa and clinical practices in the State of Iowa. Patients $18-72$ years old were eligible if they had a Crohn's disease activity index (CDAI) between 220 and 450.9 A small bowel series and colonoscopy were required within the year before enrolment. Patients continued their Crohn's disease medications if they met the following enrolment criteria: (1) mesalamine or derivatives if they had been receiving it for $>8$ weeks and the same dose for $>4$ weeks; (2) oral prednisone up to $25 \mathrm{mg} /$ day if patients had been receiving it for $>8$ weeks and the same dose for $>4$ weeks; and (3) azathioprine or 6-mercaptopurine (6-MP) if patients had been receiving it for $>6$ months and the same dose for $>8$ weeks. Before enrolment, patients had to have a haemoglobin concentration of $>10.0 \mathrm{~g} / \mathrm{dl}$, white blood count

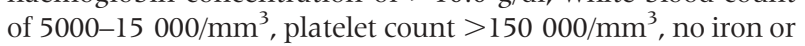
vitamin $\mathrm{B}_{12}$ deficiency, total bilirubin $<1.5 \mathrm{mg} / \mathrm{dl}$, aspartate aminotransferase and alanine aminotransferase $<100 \mathrm{U} / \mathrm{dl}$, alkaline phosphatase $<250 \mathrm{U} / \mathrm{dl}$, blood urea nitrogen $<40 \mathrm{mg} / \mathrm{dl}$, serum creatinine $<2.0 \mathrm{mg} / \mathrm{dl}$, and stool examination negative for pathogens or Clostridium difficile toxin. Women had a negative pregnancy test and practised birth control. Patients with ileostomy, colostomy, resection $>50 \mathrm{~cm}$, obstructive symptoms, or anticipated need for surgery were excluded. They were not enrolled if (1) treatment in the last 12 weeks included cyclosporine, methotrexate, infliximab, or other immunomodulatory agents, (2) treatment in the last two weeks included antibiotics, antifungal, or antiparasitic medications, and (3) they had other diseases that could interfere with compliance or interpretation of the results.

Specific pathogen free pigs were given $T$ suis ova by gastric gavage. After allowing time for worm maturation, adult worms were isolated from the colon and cultured in vitro. Ova produced in vitro were collected and allowed to embryonate for 5-6 weeks in phosphate buffered saline containing penicillin/streptomycin/amphotericin B at $22^{\circ} \mathrm{C}$. The embryonated ova were then made bacteria free using $0.2 \% \mathrm{~K}_{2} \mathrm{Cr}_{2} \mathrm{O}_{7}$, washed with sterile saline, and stored at $5{ }^{\circ} \mathrm{C}$ in phosphate buffered saline. Standard viral and bacterial cultures were performed on aliquots of ova to assure that they contained no pathogens. Pigs were inoculated with stored ova at regular time intervals to assure that the ova remained infective. This analysis demonstrated that stored ova retained viability for at least nine months. Eggs were divided into individual aliquots of 2500 . This number of ova was the same as that used in our earlier pilot study. ${ }^{10}$ Subjects returned every three weeks to drink the ova suspended in a commercial drink. The study coordinator witnessed that all of the subjects consumed the drink.

Abbreviations: $\mathrm{CDAl}$, Crohn's disease activity index; 6-MP, 6mercaptopurine; DNBS, ditrinitrobenzene sulphonic acid; TNBS, trinitrobenzene sulphonic acid 
Table 1 Baseline characteristics of the patients*

\begin{tabular}{lc}
\hline Variable & No of patients $(\mathbf{n}=29)$ \\
\hline Sex (M/F) & $13 / 16(44.8 \% \mathrm{M})$ \\
Mean age (y) & $34.0(10.8)$ \\
Smoking status (yes/total) & $9 / 29(31 \%)$ \\
Initial CDAl & $296.7(46.9)$ \\
Median duration of disease (y) & $4(1.5-8)$ \\
Site of disease & $10 / 29(34.5 \%)$ \\
Small bowel only & $5 / 29(17.2 \%)$ \\
Colon only & $14 / 29(48.3 \%)$ \\
Small bowel and colon & $5 / 29(17.2 \%)$ \\
leal resection & $5 / 29(17.2 \%)$ \\
Medications at entry & $10 / 29(34.5 \%)$ \\
No medications & $3 / 29(10.3 \%)$ \\
Mesalamine & $3 / 29(10.3 \%)$ \\
Corticosteroid & $1 / 29(3.4 \%)$ \\
Azathioprine & $1 / 29(3.4 \%)$ \\
Mesalamine+corticosteroid & $3 / 29(10.3 \%)$ \\
Mesalamine+azathioprine/6-MP & $3 / 29(10.3 \%)$ \\
Corticosteroid+azathioprine/6-MP & \\
Mesalamine+corticosteroid+ & \\
azathioprine/6-MP & \\
\hline CDAl, Crohn's disease activity index; 6-MP, 6-mercaptopurine. \\
\hline
\end{tabular}

Patients kept daily diaries of clinical symptoms. Dosing of all other inflammatory bowel disease medications was held constant. The following were obtained at entry and every six weeks: medical history and physical examination, pregnancy test, complete blood count, liver profile, and stool examination for ova, pathogens, and $C$ difficile toxin. Means (SD) are given. Medians are presented with interquartile range. The two tailed Fisher's exact test was used to examine patient characteristics that might predict response or remission.

\section{RESULTS}

A total of 29 patients were enrolled and their baseline characteristics are shown in table 1. Most patients had longstanding disease (median 3.9 (1.5-6.8) years) and were refractory to standard inflammatory bowel disease therapy before enrolment. Fourteen patients were on corticosteroids and/or azathioprine/6-MP. Only 5/29 (17\%) were on no medications; of these, 10 previously had tried corticosteroids and/or other immunosuppressants (azathioprine, 6-MP, infliximab). Mean CDAI was 294, indicating that patients were moderately ill. The cohort included patients with anatomical disease distribution similar to that of the Crohn's disease population at large.

Patients were compliant with the protocol; all patients completed their symptom diaries, attended all clinic visits, and received all doses of the ova. None was lost to follow up. Four withdrew at or before week 12 because of ongoing disease activity, and one withdrew between weeks 12 and 24 because of pregnancy. Ongoing disease activity was defined as failure to respond or achieve remission and these individuals are included in the analysis. There was no indication that the ova therapy made any patient more ill, and there were no side effects or complications attributable to therapy. Patients developed no new symptoms such as nausea, vomiting, abdominal pain, or worsening of diarrhoea. There was no deterioration in CDAI in the four patients that withdrew before week 12. Analysis of laboratory data collected during the study showed no significant changes in complete blood count or differential, blood urea nitrogen or creatinine, or aspartate aminotransferase, alanine aminotransferase, or alkaline phosphatase. All stool specimens were negative for ova and parasites.

At week 12, 22 patients $(75.9 \%)$ responded (decrease in CDAI $>100$ points or CDAI $<150)$ and $19 / 29(65.5 \%)$ were in remission (CDAI < 150). At week 24, 23 patients $(79.3 \%)$ experienced a response and $21 / 29(72.4 \%)$ were in remission
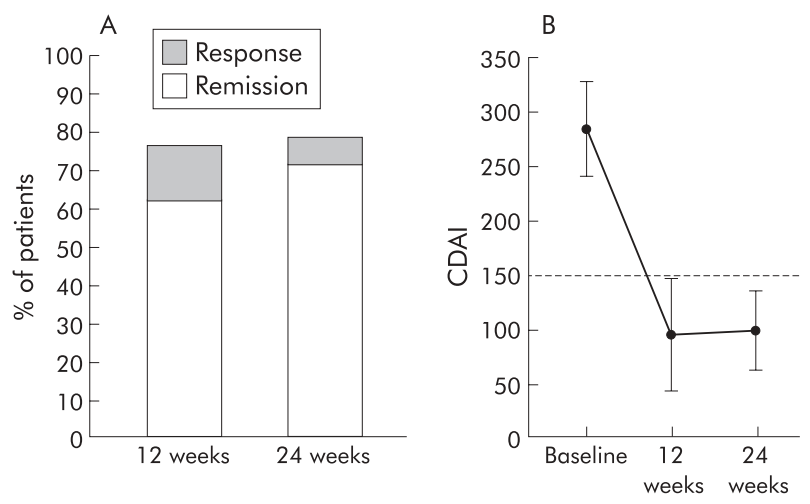

Figure 1 (A) Percentage of patients achieving remission or response at week 12 or 24 after initiating ova therapy. (B) Mean change in Crohn's disease activity index (CDAl, mean (SD)) for respondents to ova therapy. $\mathrm{CDAl}<150$ is remission. $\mathrm{p}<0.0001$, week 12 or week 24 compared with baseline (time 0).

(fig 1A). Mean initial CDAI of responders was 287.1 (47.8). It decreased to $92.0(49.2)$ at week 12 and 99.9 (35.6) at week 24 (fig 1B). Thus the mean improvement in CDAI for these patients was 195.1 and 187.2 at weeks 12 and 24 , respectively. There were six patients with a baseline CDAI between 250 and the minimum entry criterion of 220 . All six achieved both a response (improvement in CDAI of $>100$ ) and remission $($ CDAI $<150)$.

We performed subset analysis of patient characteristics looking for predictors of outcomes. Sex, patient age, disease duration, smoking status, or disease location did not influence the frequency of response or remission. There was a trend for patients using immunosuppressive drugs to improve to a greater degree than those not using these agents (table 2). Also, patients with a prior history of terminal ileum resection were less responsive.

\section{DISCUSSION}

Human helminthic parasites were considered as a therapeutic option. Many could not be used because there are no available sources other than a human carrier. Eggs from such a source would risk inadvertent transmission of pathogenic microbial agents. Also, some human helminths have disease potential or raise public health concerns.

Trichuris species are helminths with favourable characteristics for therapeutic use. Their life cycle minimises the risk of inadvertent colonisation. Trichuris ova mature in the soil and are ingested by the host. Ova hatch in the duodenum, releasing larvae that ultimately grow in 6-8 weeks into adult worms. They migrate to the terminal ileum and colon but do not invade the host. Worms can remain viable for $1-2$ years in the natural host. Adult worms release ova that are shed into the stool. These ova are immature and are not capable of colonising another host until they incubate in the soil for several weeks to allow embryonation.

We chose $T$ suis as the helminth to colonise subjects in this study. T suis, the porcine whipworm, is genetically related to $T$ trichiura, the human whipworm. T suis is not a natural human parasite but it has been shown experimentally to colonise humans briefly without causing disease. ${ }^{8}$ The ova can be produced using pathogen free pigs, and processed to assure absence of biological contaminants.

Treatment with $T$ suis ova for 24 weeks yielded a response rate of nearly $80 \%$ and a remission rate of nearly $73 \%$, which was much greater than the anticipated placebo effect. ${ }^{11-14}$ This was particularly notable as many patients had refractory disease. Thus T suis ova therapy may produce substantial and sustained improvement in active Crohn's disease. However, 


\begin{tabular}{|c|c|c|c|c|c|c|c|c|c|}
\hline \multirow[b]{2}{*}{ Group } & \multirow{2}{*}{$\begin{array}{l}\text { Total } \\
\text { No }\end{array}$} & \multicolumn{2}{|c|}{$\begin{array}{l}12 \text { weeks } \\
\text { Response }\end{array}$} & \multicolumn{2}{|c|}{$\begin{array}{l}12 \text { weeks } \\
\text { Remission }\end{array}$} & \multicolumn{2}{|c|}{$\begin{array}{l}24 \text { weeks } \\
\text { Response }\end{array}$} & \multicolumn{2}{|c|}{$\begin{array}{l}24 \text { weeks } \\
\text { Remission }\end{array}$} \\
\hline & & No & $\%$ & No & $\%$ & No & $\%$ & No & $\%$ \\
\hline \multicolumn{10}{|l|}{ Sex } \\
\hline Male & 12 & 9 & 75.00 & 8 & 66.67 & 10 & 83.33 & 8 & 66.67 \\
\hline $\begin{array}{l}\text { Female } \\
\text { p value }\end{array}$ & 17 & 13 & $\begin{array}{l}76.47 \\
1.000\end{array}$ & 11 & $\begin{array}{l}64.71 \\
1.000\end{array}$ & 13 & $\begin{array}{l}76.47 \\
1.000\end{array}$ & 13 & $\begin{array}{c}76.47 \\
0.683\end{array}$ \\
\hline \multicolumn{10}{|l|}{ Patient age } \\
\hline$<32 y$ & 14 & 12 & 85.71 & 11 & 78.57 & 12 & 85.71 & 11 & 78.57 \\
\hline$\geqslant 32 y$ & 15 & 10 & 66.67 & 8 & 53.33 & 11 & 73.33 & 10 & 66.67 \\
\hline$p$ value & & & 0.390 & & 0.245 & & 0.651 & & 0.682 \\
\hline \multicolumn{10}{|l|}{ Disease duration } \\
\hline$<3.9$ years & 14 & 12 & 85.71 & 11 & 78.57 & 12 & 85.71 & 12 & 85.71 \\
\hline$\geqslant 3.9 y$ & 15 & 10 & 66.67 & 8 & 53.33 & 11 & 73.33 & 9 & 60.00 \\
\hline$p$ value & & & 0.390 & & 0.245 & & 0.651 & & 0.215 \\
\hline \multicolumn{10}{|l|}{ Current smoking status } \\
\hline Non-smoker & 20 & 15 & 75.00 & 13 & 65.00 & 16 & 80.00 & 15 & 75.00 \\
\hline Smoker & 9 & 7 & $\begin{array}{l}77.78 \\
1.000\end{array}$ & 6 & $\begin{array}{l}66.67 \\
1.000\end{array}$ & 7 & $\begin{array}{l}77.78 \\
1.000\end{array}$ & 6 & $\begin{array}{c}66.67 \\
0.675\end{array}$ \\
\hline \multicolumn{10}{|l|}{ Disease location } \\
\hline Small bowel only & 14 & 11 & 78.57 & 10 & 71.43 & 11 & 78.57 & 10 & 71.43 \\
\hline Small bowel and colon & 8 & 5 & 62.50 & 5 & 62.50 & 6 & 75.00 & 6 & 75.00 \\
\hline Colon only & 7 & 6 & 85.71 & 4 & 57.14 & 6 & 85.71 & 5 & 71.43 \\
\hline \multirow{2}{*}{\multicolumn{10}{|c|}{ Ileal resection }} \\
\hline & & & & & & & & & \\
\hline Resection & 5 & 2 & 40.00 & 2 & 40.00 & 2 & 40.00 & 2 & 40.00 \\
\hline No resection & 24 & 20 & 83.33 & 17 & 70.83 & 21 & 87.50 & 19 & 79.17 \\
\hline$p$ value & & & 0.075 & & 0.306 & & 0.046 & & 0.112 \\
\hline \multicolumn{10}{|c|}{ Use of immuosuppressives ${ }^{*}$} \\
\hline Not using & 15 & 9 & 60.00 & 9 & 60.00 & 9 & 60.00 & 9 & 60.00 \\
\hline Currently using & 14 & 13 & 92.86 & 10 & 71.43 & 14 & 100.00 & 12 & 85.71 \\
\hline$p$ value & & & 0.080 & & 0.700 & & 0.017 & & 0.215 \\
\hline
\end{tabular}

the study was open label, and we cannot exclude a high placebo effect. The treatment caused no side effects or complications even in patients receiving multiple immunosuppressants (for example, corticosteroids and azathioprine/ 6-MP), suggesting a high safety profile.

Subset analysis of the data suggested that patients on immunosuppressive therapy faired better, as did patients with an intact terminal ileum. We can only speculate on the reason for these observations. It is possible that immunosuppressives could have influenced T suis colonisation. Also, there could have been a synergistic interaction between the immunomodulatory effect of the helminths and the immunosuppressive effect of the other drugs. Terminal ileal resection also could have affected worm colonisation, or perhaps residual symptoms from the surgery confounded CDAI scoring. Both of these observations need confirmation in a prospective trial to assure that they were not artefacts.

There is an immunological basis to expect that exposure to helminths such as $T$ suis will prove beneficial in Crohn's disease. Crohn's disease involves over reactive Thl pathways, and helminths blunt Thl responses. For example, helminths attenuate intestinal inflammation in animal models of inflammatory bowel disease. Interleukin 10 deficient mice spontaneously develop a Thl-type colitis characterised by infiltration of the lamina propria with interferon $\gamma$ producing CD4+ T cells. ${ }^{15}$ Colonisation with $T$ muris or Heligmosomides polygyrus retards development of colitis in interleukin 10 deficient mice. ${ }^{1}$ Mice and rats treated with di- or trinitrobenzene sulphonic acid (DNBS, TNBS) develop a Thl cytokine driven colitis that shares features with Crohn's disease. ${ }^{16}$ Mice and rats exposed to Schistosoma mansoni are resistant to TNBS colitis. ${ }^{67}$ Colonisation of mice with Trichinella spiralis diminishes DNBS induced colits. ${ }^{5}$ This protection is associated with decreased systemic and colonic interferon $\gamma$ and interleukin 12 expression, which are critically important Thl cytokines.
Colonisation with helminths augments several immunoregulatory pathways that limit Thl-type inflammation. Helminths induce production of interleukin 4 and interleukin 13, which are Th2 cytokines. This Th2 response inhibits production of Thl cytokines thereby reducing colitis severity. ${ }^{6}$ Helminths also induce regulatory $\mathrm{T}$ cells and immune regulatory substances such as transforming growth factor $\beta$, interleukin 10, and prostaglandin $\mathrm{E}_{2}$ that assist in maintaining host mucosal homeostasis. ${ }^{4}$

In summary, T suis is well tolerated and appears efficacious for Crohn's disease in this open label trial. Helminths probably inhibit intestinal inflammation by mechanisms different from current medications. Helminths may offer an easy to administer alternative or supplement to currently available therapeutic agents. These results justify a double blind controlled clinical trial. Furthermore, these results support the hypothesis that helminthic exposure provides protection against some immune mediated inflammatory disease like Crohn's disease.

\section{ACKNOWLEDGEMENTS}

The authors gratefully acknowledge the support of Betty Musgrave, clinical research coordinator. Drs Miriam B Zimmerman and William Clarke, Department of Biostatistics provided assistance with study design, statistical methods, and data analysis. Additional participating University of Iowa gastroenterologists included Drs Jeffrey Field, Khurram Qadir, and David Ramkumar. Collaborating gastroenterologists from the State of Iowa included: Drs Dean Abramson, Nile Dusdieker, Joseph Ewing, Jon Gibson, Bernard Leman, Randall Lengeling, Sudhakar Misra, James Piros, Douglas Purdy, Leon Qiao, Surish Reddy, Robert Silber, Joseph Truszkowski, and Gary Weinman.

The Crohn's and Colitis Foundation of America provided the primary support for this study. The Broad Medical Research Program of the Eli and Edythe L Broad Foundation, the Ed and Liliane Schneider Family Foundation, and the Thomas Irwin Memorial Fund also provided partial support. The study sponsors had no involvement in the study design, collection, analysis, and interpretation of the 
data, in the writing of the report; or in the decision to submit the paper for publication.

\section{Authors' affiliations}

R W Summers, D E Elliott, R Thompson, J V Weinstock, James A Clifton Center for Digestive Diseases, Department of Internal Medicine, University of lowa Roy J and Lucille Carver College of Medicine, University of lowa, lowa City, lowa, USA

J F UrbanJr, Nutrient Requirements and Functions Laboratory, Beltsville Human Nutrition Research Center, Agricultural Research Service, United States Department of Agriculture, Beltsville, Maryland, USA

Conflict of interest: None declared.

\section{REFERENCES}

1 Elliott DE, Urban JF Jr, Argo CK, et al. Does the failure to acquire helminthic parasites predispose to Crohn's disease? FASEB J 2000; 14:1848-55.

2 Sabin EA, Araujo MI, Carvalho EM, et al. Impairment of tetanus toxoidspecific Th1-like immune responses in humans infected with Schistosoma mansoni. J Infect Dis 1996; 173:269-72.

3 Borkow G, Leng Q, Weisman Z, et al. Chronic immune activation associated with intestinal helminth infections results in impaired signal transduction and anergy. J Clin Invest 2000;106:1053-60.

4 Weinstock JV, Summers R, Elliott DE. Helminths and harmony. Gut 2004;53:7-9.

5 Khan WI, Blennerhasset PA, Varghese AK, et al. Intestinal nematode infection ameliorates experimental colitis in mice. Infect Immun 2002;70:5931-7.
6 Elliott DE, Li J, Blum A, et al. Exposure to schistosome eggs protects mice from TNBS colitis. Am J Physiol 2003;284:G385-91.

7 Moreels TG, Nieuwendiijk RJ, De Man JG, et al. Concurrent infection with Schistosoma mansoni attenuates inflammation induced changes in colonic morphology, cytokine levels, and smooth muscle contractility of

trinitrobenzene sulphonic acid induced colitis in rats. Gut 2004;53:99-107.

8 Beer RJ. The relationship between Trichuris trichiura (Linnaeus 1758) of man and Trichuris suis (Schrank 1788) of the pig. Res Vet Sci 1976;20:47-54

9 Best WR, Becktel JM, Singleton JW, et al. Development of a Crohn's disease activity index. National Coorperative Crohn's Disease Study. Gastroenterology 1976;70:439-44.

10 Summers RW, Elliott DE, Qadir K, et al. Trichuris suis seems to be safe and possibly effective in the treatment of inflammatory bowel disease. Am J Gastroenterol 2003;98:2034-41.

11 Sands BE, Winston BD, Salzberg B, et al. Randomized, controlled trial of recombinant human interleukin-11 in patients with active Crohn's disease. Aliment Pharm Ther 2002;16:399-406.

12 Sandborn WJ, Feagan BG, Hanauer SB, et al. An engineered human antibody to TNF (CDP571) for active Crohn's disease: a randomized doubleblind placebo-controlled trial. Gastroenterology 2001;120:1330-8.

13 Panaccione R, Canadian Consensus Group on the use of infliximab in Crohn's disease. Infliximab for the treatment of Crohn's disease: review and indications for clinical use in Canada. Can J Gastroenterol 2001;15:371-5.

14 Feagan B. Infliximab in the treatment of Crohn's disease. Can J Gastroenterol 2000;14(suppl C):6C.

15 Berg DJ, Davidson N, Kuhn R, et al. Enterocolitis and colon cancer in interleukin-10-deficient mice are associated with aberrant cytokine production and CD4(+) TH1-like responses. J Clin Invest 1996;98:1010-20.

16 Neurath MF, Fuss I, Kelsall BL, et al. Antibodies to interleukin 12 abrogate established experimental colitis in mice. J Exp Med 1995;182:1281-90.

\section{EDITOR'S QUIZ: GI SNAPSHOT}

\section{Vomiting in the recently anticoagulated patient}

\section{Clinical presentation}

A 42 year old previously healthy man presented with an eight hour history of retrosternal tightness. While clinical examination was unremarkable, his cardiac enzymes were raised and his electrocardiogram showed ST segment elevation in leads II, III, and aVf. He was diagnosed with an acute inferior myocardial infarction and received 1.5 million units of streptokinase over the next hour. His pain settled and he was comfortable overnight.

The following morning he developed epigastric pain and tenderness and vomited twice. His haemoglobin level dropped to $12 \mathrm{~g} / \mathrm{dl}(15 \mathrm{~g} / \mathrm{dl}$ on admission). Although overall he improved over the next 48 hours, he continued to vomit even though fasting. An upper gastrointestinal endoscopy was preformed and demonstrated the duodenal abnormality shown in fig 1.

\section{Question}

What is the abnormality shown (fig 1) and what is the most appropriate course of subsequent treatment? See page 102 for answer

This case is submitted by:

R A Cahill, S Siddique, J O'Connor Department of General Surgery, Waterford Regional Hospital, Waterford, Ireland

Correspondence to: Mr R Cahill, Department of General Surgery, Waterford Regional Hospital, Waterford, Ireland; rcahill@rcsi.ie
Robin Spiller, Editor

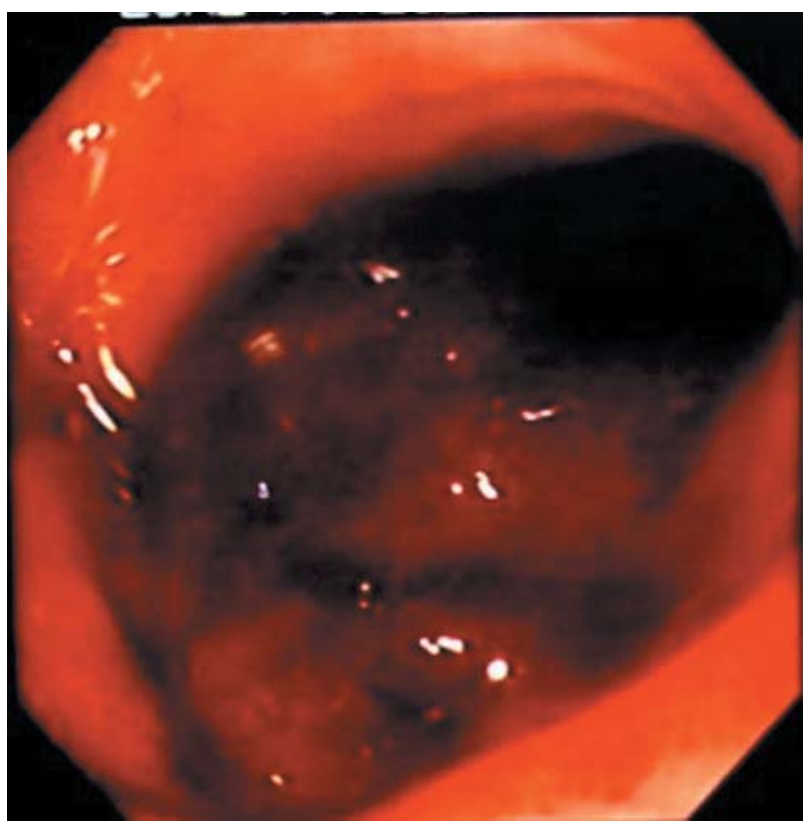

Figure 1 Upper gastrointestinal endoscopy. 